\title{
Imagens, crenças e verdade nas manifestações de 2013 e 2015
}

\section{Images, beliefs and truth at the 2013 and 2015 protests $^{1}$}

Vera Veiga França², Mayra Bernardes ${ }^{3}$

1 A primeira versão deste texto foi apresentada no seminário Polarizações, promovido pelo Grupo de Pesquisa Mídia e Narrativa, da Pontifícia Universidade Católica de Minas Gerais (PUC Minas), em Belo Horizonte, de 3-5 de novembro de 2015. Reflexão ligada ao projeto Valores em movimento no cenário midiático-social: leitura dos acontecimentos e da intervenção pública dos sujeitos, financiado pelo CNPq.

2 Professora do Programa de Pós-Graduação em Comunicação Social da Universidade Federal de Minas Gerais (UFMG). Bolsista Pq1-B do CNPq. E-mail: veravfranca@yahoo.com.br.

3 Bolsista de iniciação científica e coautora do artigo como parte de sua monografia de conclusão de pesquisa. E-mail: mayrabernardesc@gmail.com. 


\section{Resumo}

Este texto relaciona dois acontecimentos marcantes na história brasileira contemporânea: as jornadas de junho de 2013 e as manifestações próimpeachment de 2015. A partir dos conceitos de face, verdade e violência, organizamos um percurso analítico em três etapas: um olhar sobre as jornadas de junho, uma leitura das manifestações de 2015 a partir de fotografias e uma reflexão sobre as implicações e desdobramentos de 2013 nas manifestações de 2015.

\section{Palavras-chave}

Manifestações, imagens, política. 
This article links two remarkable occurrings in Brazil's contemporary history: the 2013's "jornadas de junho" and the 2015's pro-impeachment protests. Through the concepts of front, truth and violence, we organize an analytic route in three stages: a look over the "jornadas de junho", a perusal at the 2015 's protests through photographs and a reflection on the implications and unfoldings of 2013 found in 2015's protests.

\section{Keywords}

Protests, images, politics. 
Este texto reúne dois momentos da sociedade brasileira e dois momentos de nossa reflexão: 2013, com as chamadas "jornadas de junho", e 2015, quando ocorreram quatro grandes manifestações a favor do impeachment da presidente Dilma. Em 2013, ainda no impacto dos movimentos de rua que surpreenderam o país, a indagação que fizemos foi marcada sobretudo pela expectativa quanto a seus desdobramentos. Em 2015, perplexas com o enquadramento tomado pela nova movimentação, entendemos que, não sendo a mesma coisa, um e outro acontecimento estavam ligados, e as manifestações de 2015 constituíam, de alguma forma, um dos vários desdobramentos de 2013. O acontecimento de 2015, que prolonga um quadro de polarização criado nas eleições de 2014, convoca, como seu passado, também a insatisfação que aflorou e ganhou forma em 2013.

É preciso antes explicitar (por redundante que seja fazê-lo!) que nossa leitura dos fatos, como toda análise da realidade, parte de uma dada perspectiva. Somos sujeitos inseridos no mundo que estamos analisando, e assim, olhamos necessariamente a partir de um lugar. Cumpre dizer que nossa perspectiva é crítica com relação à configuração tomada pelo posicionamento daqueles que, com legítimo direito, fazem oposição à presidenta Dilma e à política que vem sendo implementada no país desde o governo Lula. Na presente reflexão organizamos um percurso em três tópicos: um olhar sobre as jornadas de junho; uma leitura das manifestações de 2015 a partir das fotografias dos eventos publicadas por portais on-line de notícias, seguidos de uma breve conclusão.

\section{A face e a "verdade" das jornadas de junho de 2013}

De forma provocativa, esse foi o título da reflexão apresentada em 2013, tanto tocando na polêmica noção de verdade como colocando em xeque a veracidade daquilo que se dá a ver - forçando uma oposição que, como procuraremos demonstrar a seguir, não se coloca nesses termos.

\section{A face}

Usamos o conceito de "face" no sentido evocado por Goffman (1996): tratase da fachada, daquilo que se realiza na frente do outro, da imagem que se dá a ver. O conceito aciona e articula dois aspectos: a) a dimensão empírica dos fatos; b) a evocação de quadros de sentido. O tratamento da face nos remete inicialmente à dimensão empírica do fenômeno; diz respeito à concretude das coisas, à sua existência para além das representações que possamos acionar.

Quando pensamos nas manifestações que aconteceram em 2013, evocamos antes de tudo sua concretude - a maneira como "coisas" aconteceram e afetaram o ambiente à nossa volta. Nós vimos multidões nas ruas, em grandes e pequenas 
cidades do país; a mídia produziu e circulou imagens impactantes, que podem ser revistas. Soubemos da intervenção de forças policiais e de enfrentamentos (ou a presenciamos); ações violentas foram realizadas, como a destruição de edificações, prisões, espancamentos. Vimos imagens de um público diferenciado, com a predominância e protagonismo dos jovens. Uma pauta plural abarcou as mais diferentes palavras de ordens, faixas, evocações.

Porém, ao lado da "concretude" de fatos que se deram a ver e foram vivenciados, uma outra dimensão sobressai. Acontecimentos acontecem a pessoas, que se veem convocadas a interpretá-los, a tentar compreender o que se passa. Quando se tornam fatos "para nós", e na proporção mesma em que nos afetam, eles passam a ser enquadrados e narrativizados. Todo esforço de compreensão é um trabalho de buscar sentidos, de aproximar aquilo que acontece de modelos já existentes, de alcançar categorias explicativas. A pergunta que surge no momento em que se está vivenciando um acontecimento é: o que é isto? O que está acontecendo? Tais indagações visam inserir a situação experimentada dentro de "quadros de sentido" (BATESON, 2002; GOFFMAN, 2012), uma ordem de inteligibilidade que nos permite compreender o que se passa e ajustar nossa conduta. Tais quadros - a resposta sobre o que está acontecendo - não são individuais, mas sociais. É a existência de um repertório comum (de ordem cultural e histórica) que nos auxilia a promover o enquadramento do novo, narrá-lo dentro de um enredo compartilhado.

A mídia e todos que viveram aquele momento buscaram formas de compreender e narrar o que estava acontecendo. Experiências do passado foram evocadas: os caras-pintadas em 1990, o movimento de Maio de 68, até mesmo acontecimentos de maior magnitude, como a Queda da Bastilha, estopim simbólico da revolução francesa.

O trabalho de identificação, porém, vai além de buscar uma referência e promover uma associação: frente à irrupção inesperada das manifestações, era preciso inserir as ocorrências em uma dinâmica maior, da qual elas seriam um desdobramento. Se os primeiros fatos se relacionavam com a luta do Movimento Passe Livre, rapidamente seus desdobramentos mostraram uma envergadura que ultrapassou largamente o movimento contra o aumento das passagens, prefigurando um fenômeno mais amplo (RODRIGUES, 2015). As jornadas de junho (somando-se a outros movimentos de contestação que ocorreram em diversos países) seriam algo mais extenso e mais profundo, uma intervenção política da chamada geração Facebook, manifestando-se e lutando contra a falência das instituições tradicionais em sua capacidade de atender às expectativas dos novos sujeitos sociais. 
Causas específicas foram apontadas no caso brasileiro: se até 2012 parecia que tudo ia mais ou menos bem, 2013 descortina uma realidade problemática, em que se destacam as precariedades da vida urbana, o descrédito dos políticos e da política institucional, os limites da ascensão social e o estreitamento dos projetos de vida. De repente a sociedade, e principalmente sua juventude, se deram conta de sua insatisfação com a democracia representativa, com a falta de participação política; com a ausência de utopias e com o vazio deixado pela falta de grandes projetos. Algumas questões ganharam sentido de urgência naquele momento: que tipo de intervenção estamos tendo não apenas na construção de nosso presente, mas sobretudo na configuração de nosso futuro? Estamos caminhando para onde? Qual é o horizonte que nos espera?

No enquadramento e categorização do que estava acontecendo, diversos especialistas buscaram identificar as características dessas manifestações, e vários aspectos foram arrolados (CASTELLS, 2013; NOGUEIRA, 2013). No que diz respeito à composição sociodemográfica, observou-se a diversidade intergeracional dos manifestantes, com predominância juvenil; um viés interclassista e interétnico. Foi um movimento de alcance nacional, ocorrendo em todas as regiões do país. Se ele caracterizou-se por uma inusitada ocupação das ruas, foi também marcado pelo uso intensivo das novas mídias (antes, durante e depois dos atos: para convocação, para registro e compartilhamento). Assumiu tanto um caráter festivo quanto uma face violenta (a repressão policial, ações de depredação por parte de grupos etc).

Do ponto de vista da orientação política, é também a diversidade o traço dominante. O movimento tanto foi interpartidário como, em alguns momentos, antipartidário. Foi um movimento multitemático, descentralizado, no qual sobressaíram a ausência de lideranças fortes e a presença/surgimento de coletivos de discussão. A classe política se viu marginalizada, acuada e indecisa.

Se as manifestações ocuparam inteiramente a pauta midiática e a agenda da sociedade, eles também suscitaram controvérsias quanto ao que significavam e para onde apontavam.

Tais aspectos - a convocação de experiências passadas, a inscrição em um contexto mais amplo, a busca das causas, o levantamento de características - nos ajudam a recompor o que podemos chamar "a face" das jornadas de junho de 2013. Como destacamos, a constituição da face alia e organiza elementos empíricos numa representação mais ou menos coerente, em uma imagem reconhecível (a face, portanto, tem uma composição tanto empírica como sociossimbólica).

Contudo, o que também se destaca de nossa leitura é o caráter diversificado dessa face, a presença de elementos contraditórios - e, no entanto, complementares -, o que leva ao segundo momento dessa reflexão: qual sua "verdade"? 


\section{A verdade}

Falar na "verdade" das jornadas de junho é uma afirmação provocativa, que toca num terreno polêmico. Verdade é, hoje, uma ideia desacreditada, e ela desvaneceu-se com a própria falência das certezas científicas, da precariedade dos conceitos explicativos totalitários, da compreensão de que nosso mundo, marcado pela complexidade, atravessado pelas incertezas, assombrado pela entropia e pelo caos (conforme discutido por autores como Edgar Morin, Ilya Prigonine, Isabelle Stengers, entre outros).

Por outro lado, também é preciso recusar o relativismo, que não ajuda o conhecimento, que impede o desenvolvimento de um pensamento crítico e pulveriza o próprio terreno da convivência (se tudo pode ser verdade, nada é verdade, e tudo vale. Tal relativismo mina as bases de construção de um mundo comum e empobrece o conhecimento).

Essa dupla negação (nem verdade absoluta nem relativismo) nos deixa em um lugar desconfortável, e fomos buscar apoio no pragmatismo de Peirce e James, mais especificamente na Teoria da Verdade de William James, conforme nos é apresentada sobretudo por Madelrieux (2008) e Putnam (2010).

Para James (no clássico Pragmatism: a new name for some old ways of thinking, 1902), a verdade é uma concordância com a realidade; não uma concordância individual, mas uma concordância coletiva, um consenso social. Nesse sentido, a verdade não é intrínseca a uma ideia, mas ela "acontece" a uma ideia. Ela é definida em termos de "consenso último", e é uma propriedade de crenças e juízos.

A "concordância com a realidade", para os autores, não é sinônimo de correspondência; inexistem parâmetros equivalentes para falar em correspondência, já que esta ignora contextos em evolução. James fala em "relações conjuntivas", relações exteriores que podem ser observadas para conectar nossas ideias àquilo a que elas se referem. Uma ideia não gruda em uma coisa por suas qualidades intrínsecas ou por um impulso solitário da subjetividade de um sujeito, mas sim como resultado de uma conjunção de elementos, de uma relação que se estabelece fora da consciência individual entre coisas e outras ideias que circulam (PUTNAM, 2010).

Nessa dinâmica, as coisas ganham significação. Para os pragmatistas, o significado de um objeto são seus efeitos práticos; a significação é uma operação, e não um conteúdo. Diferentemente do empirismo clássico, para o qual a significação está na origem (no objeto) e é resultado de uma percepção sensível, para James ela está no destino e é resultado de operações desenvolvidas ao longo da experiência. 
É nesse movimento que as ideias chegam a concordar com a realidade: operações, executadas por uma coletividade, levam ao estabelecimento de significados, que se identificam com a experiência vivida, que dizem das consequências práticas da transação com a coisa significada.

Como resultado desse processo, a verdade "acontece" com uma ideia. As operações que fazem com que uma ideia "se torne" verdade são operações de conhecimento levadas a cabo por um sujeito guiado por interesses.

O conhecedor não é simplesmente um espelho flutuando sem nenhuma base em lugar algum, e reflete passivamente uma ordem com a qual ele se depara e a qual ele encontra simplesmente existindo. O conhecedor é um ator, um coeficiente da verdade, por um lado, ao passo que por outro ele registra a verdade que ajuda a criar. Os interesses mentais, as hipóteses, os postulados, na medida em que são as bases para a ação humana - uma ação que em grande medida transforma o mundo -, ajudam a produzir a verdade que eles declaram (JAMES [1878], apud PUTNAM, 2010, p. 213).

São operações guiadas por interesses, por conhecimentos prévios, permanentemente ajustadas aos resultados de uma experiência.

No bojo de uma experiência, se duas ou mais ideias são convocadas para expressar aquela experiência (ou suas consequências), prevalece aquela que atende melhor ao encaminhamento da ação. Conforme James (1905, p. 75), "de duas concepções igualmente aptas a satisfazer a demanda lógica, aquela que desperta os impulsos ativos ou satisfaz outras demandas estéticas melhor que a outra será considerada a concepção mais real e merecidamente prevalecerá".

Essa que prevalece é resultado de consensos últimos de uma comunidade. Esse processo, porém, não é fácil; James nos diz que a comunidade não é livre para construir o consenso - e que essa construção é coagida tanto pela realidade como por um conjunto de crenças prévias. Crenças moldam nosso pensamento (PUTNAM, 2010, p. 213) - mas elas, por sua vez, são resultado de ações bem-sucedidas. É verdade aquilo que serve para nossa ação, e ações bem-sucedidas formulam crenças, por meio das quais lemos a realidade e empreendemos novas ações.

Ora, como dizer então da "verdade" das jornadas de junho? Seguindo James, não encontramos uma resposta, mas pistas. "A significação não está na origem, mas no destino", o que nos leva a dizer: não existia algo antes, ou por debaixo das ações, conferindo seu significado final. A significação das jornadas de junho se remete às suas consequências práticas. Sua verdade não estava dada, mas acontecendo. Ela estava por vir, tecida pelos desdobramentos práticos e pelos 
consensos que eles viessem a provocar; seria resultado das consequências e da avaliação das consequências, consolidando ou reformulando crenças e juízos.

Naquele momento e imediatamente após, leituras diversas circulavam. Prenúncios de desdobramentos se deram a ver: coletivos que se formaram e/ ou se fortaleceram, como o Mídia Ninja, as ações black bloc (DORNELAS, 2015); movimentos de reivindicação ganharam algum recrudescimento (como a greve dos professores da Rede Municipal do Rio de Janeiro). Naquele ano não se poderia dizer ainda o que nos aguardava, que tipo de crenças e consensos estavam se cristalizando, motivando quais modalidades de ação.

\section{Manifestações de 2015: imagens controversas dos cidadãos de bem}

Ao longo de 2014, com um breve intervalo para o período da Copa do Mundo de Futebol, o cenário das eleições presidenciais nos brindou com um longo segundo semestre: embate de candidatos, morte de Eduardo Campos, ascensão e queda da candidatura de Marina Silva, movimentação e cruzamento das alianças interpartidárias. Dois candidatos (Dilma Rousseff, PT, e Aécio Neves, PSDB) foram para o segundo turno, num clima de forte polarização, que não foi dissolvida, mas agudizada, com a vitória da candidata da situação, Dilma Rousseff, por uma margem de apenas 3\%.

O resultado das eleições e a derrota da oposição não foram aceitos, e a continuidade da disputa desenhou o cenário do ano de 2015 e das novas manifestações que passaremos a analisar.

Esse cenário herda parte de sentimentos gerados em 2013 - a insatisfação, o desencanto -, que germina e ganha formas e perfis diferenciados. A manifestação difusa e plural dos desejos de mudança, uma mudança que (ainda) não havia se concretizado, se desdobrou em uma pauta dupla e excludente: a mudança como avanço, a mudança como retorno.

Para alguns, as transformações desejadas apontavam para uma intensificação das mudanças - reforma política, redirecionamento da política econômica, estabelecimento de políticas públicas comprometidas com a ampliação dos direitos sociais, da participação política, do respeito à diversidade. Para outros, tratava-se justamente de conter os avanços sociais e as medidas que afetavam a manutenção de privilégios e da distância social.

Os dois segmentos se cristalizaram, e foi o segundo, de mudança como retorno, que ganha as ruas, promovendo manifestações contra Lula e o PT e pelo afastamento da presidenta Dilma Rousseff. Se 2013 abriu uma pauta plural e registrou a inexistência de um consenso quanto ao que estava por vir, 2014 registrou uma polarização e a radicalização dos lados. 
As manifestações pelo impeachment de 2015 representaram a consolidação de um desses lados, que recupera sentimentos de permanência fortemente arraigados na sociedade e presentes em nossa história (1954, 1964). O cenário e ações empreendidas em 2015 indicavam a construção de um consenso e de uma intervenção concertada por parte de segmentos da sociedade brasileira (sobretudo da classe média branca, de uma faixa etária adulta), firmemente ancorados em algumas crenças que adquirem - se tornam - verdade.

As manifestações construíram uma face sustentada pelo discurso dos manifestantes e pela mídia: manifestações pacíficas, empreendidas por cidadãos de bem, pelo bem do Brasil. Através da leitura de algumas imagens veiculadas pela mídia, buscaremos, a seguir, empreender uma análise dessa face buscando revelar, para além das evidências, as crenças que as sustentavam, ou a sua verdade. Não se trata, certamente, de opor verdade a aparência, mas identificar a verdade no consenso, nas convicções que unificavam os discursos e os manifestantes.

\section{Manifestações pacíficas, cidadãos do bem}

Aqui buscaremos identificar o enquadramento que foi dado às manifestações, através dos cenários, vestuário e comportamento dos manifestantes fotografados e veiculados pela mídia. Nesse aspecto, é fundamental registrar o forte contraste entre as imagens de 2013 e as imagens de 2015. Embora não apenas nisso, o contraste se dá inicialmente em torno do caráter violento e/ou pacífico de cada uma delas.

O cenário midiático predominante de 2013 foi marcado pela violência, que tomava forma física através da truculência policial, da depredação do patrimônio público e privado, e daquilo que a mídia chamou de vandalismo. Bombas de gás lacrimogênio, spray de pimenta, balas de borracha, confrontos com a polícia, pessoas feridas, barricadas, imóveis danificados, carros queimados eram elementos muito fotografados, dando um tom escuro e de revolta a esses eventos.

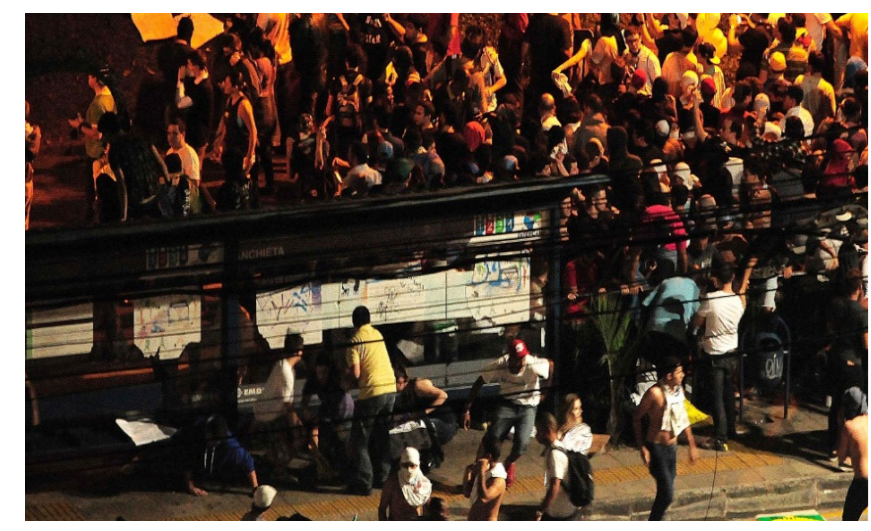

Figura 1: Manifestantes e policiais entram em confronto durante protesto em Campinas. Créditos: Rodrigo Villalba/Futura Press, via UOL. 


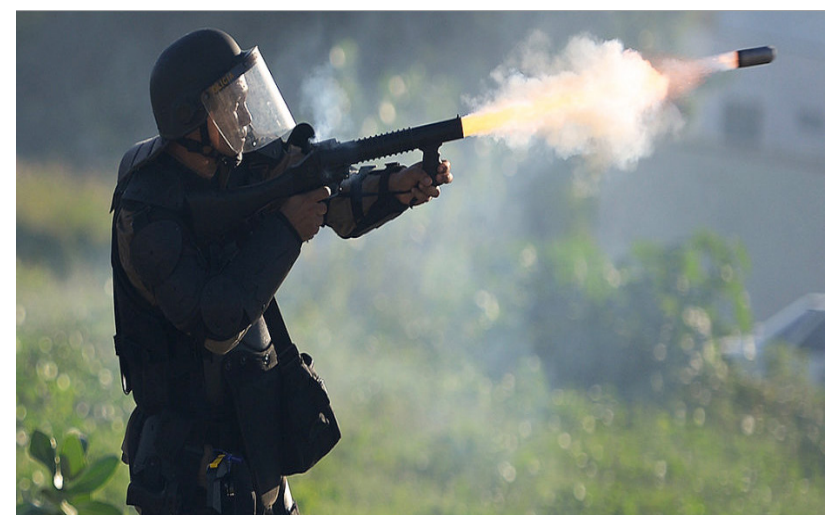

Figura 2: Policial joga uma bomba de gás lacrimogêneo contra manifestantes. Créditos: Yasuyoshi Chiba/AFP/Veja.

Ao lado de policiais fortemente armados, manifestantes com o rosto encoberto e lançando coquetéis molotov foram situações muito exploradas pela cobertura midiática. Nas fotografias, eles aparecem com o rosto e corpo cobertos por roupas de cores escuras, executando ações de ataque e defesa, numa dicotomia desenhada pela mídia como manifestantes pacíficos versus vândalos. Essa distinção se traduziu na separação de grupos, e chegou a virar um cântico, "sem violência", através do qual parte dos manifestantes procurava afastar grupos que adotavam a tática black bloc e deles se distinguir.

Nas manifestações de 2015, o espírito "contra a violência" foi internalizado pelos movimentos que organizaram as manifestações e pelos manifestantes pró-impeachment, que caminharam tranquilamente pelos principais pontos turísticos dos grandes centros urbanos brasileiros escoltados pela polícia militar. Os protestos de 2015 não são acusados de obstruírem o trânsito e de causar transtornos nem de vandalismo.

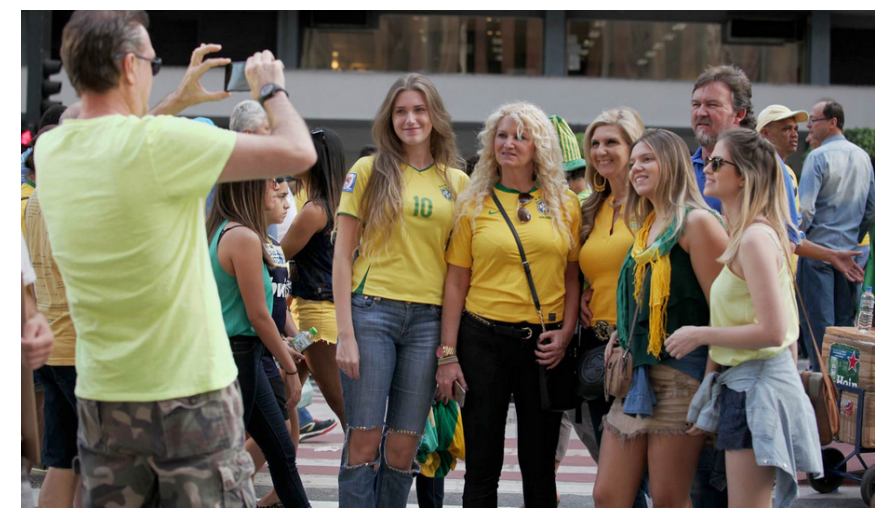

Figura 3: Manifestantes tiram foto durante protesto contra a presidente Dilma Rousseff. Créditos: Fábio Tito/G1. 


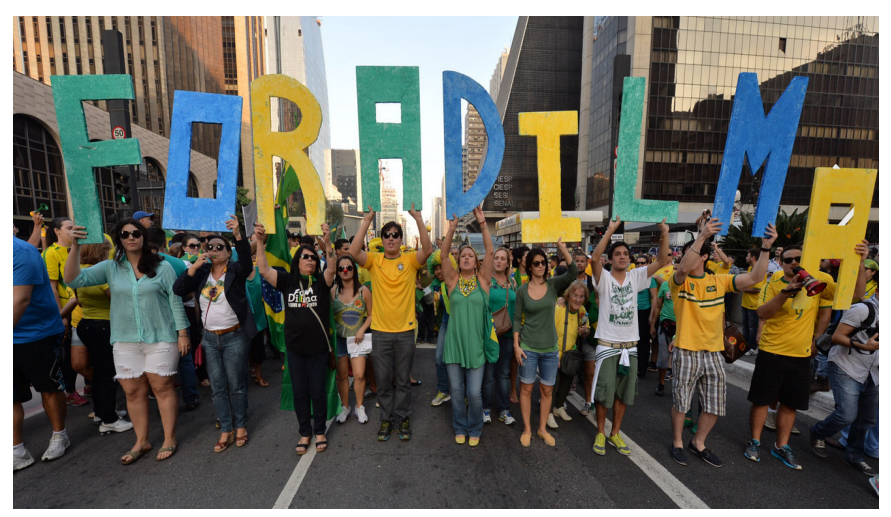

Figura 4: Protesto na avenida Paulista, em São Paulo. Créditos: Nelson Almeida/AFP, via Veja.

O cenário midiático apresentado pela mídia é leve, com um tom quase festivo, lembrando fotografias das torcidas na Copa do Mundo de Futebol de 2014. As fotografias publicadas mostram manifestantes sorrindo, fazendo selfies (inclusive com a polícia), mostrando o rosto e o corpo, acompanhados por seus filhos, animais de estimação e parentes idosos, vestidos com roupas de passeio e portando objetos de manifestação diferentes daqueles encontrados em 2013: faixas personalizadas, bonecos, cornetas, adereços festivos, colheres e panelas.

\section{A violência simbólica}

Cabe, no entanto, perguntar até que ponto essas manifestações foram realmente pacíficas. Ao lado do cenário aparentemente festivo, uma extensa produção discursiva se materializou em objetos e ações, traduzindo uma outra forma de violência.

Não houve, ou não predominou nenhum tipo de violência física nos moldes de 2013 (uso da força bruta pela política, depredação de edificações pelos manifestantes) ${ }^{4}$. A violência, no entanto, pode se apresentar de várias formas (ZIZEK, 2014); a leitura das imagens dos cidadãos pacíficos sugere a presença insidiosa da violência simbólica, ou seja, da violência que se dá através de formas discursivas que promovem a representação negativa e/ou a coação do outro, que indicam intolerância e ódio.

Vemos, nas fotografias, que ao lado de um discurso que enuncia a natureza pacífica dos manifestantes (sorrindo e posando de forma descontraída para as câmeras), ecoam proferimentos nada suaves contra Dilma Rousseff, contra o Partido dos Trabalhadores e suas figuras mais proeminentes.

\footnotetext{
4 Alguns episódios de violência física foram registrados e denunciados, como o espancamento de indivíduos que manifestaram (ou sugeriam) posicionamento contrário ao impeachment ou proximidade com o PT. Isso não será tratado aqui, pois nosso corpus se refere a imagens veiculadas pelas mídias já mencionadas.
} 
Aparece, assim, uma imagem controversa: ao mesmo tempo que se reforça a representação do "cidadão de bem", não baderneiro, encontramos também elementos que traduzem discursos de ódio e violência, como caixões com o nome do PT e fotos de Dilma e Lula, bonecos representando Dilma e Lula sendo agredidos, torturados e mortos, além de faixas que exaltam a violência do período da ditadura militar e incitam a perseguição aos chamados "comunistas vermelhos".

Esse discurso agressivo, no entanto, é justificado em nome de valores tidos como nacionalistas. Os manifestantes se vestem de verde e amarelo da cabeça aos pés, usam a bandeira do Brasil amarrada ao corpo e como fundo de banners, cantam o hino nacional repetidas vezes e ressignificam as cores do Brasil e outros símbolos nacionais em apoio à causa ali defendida.

Em contrapartida, colocam o vermelho - cor símbolo do PT, dos partidos de esquerda e da campanha presidencial de Dilma Rousseff em 2014 - como a cor dos comunistas, que, ressuscitando o clima da Guerra Fria, são inimigos e devem ser perseguidos e combatidos. O retorno dessa construção histórica é tão forte que, nessas manifestações, pessoas foram agredidas física e verbalmente e expulsas do espaço apenas por estarem usando roupas ou acessórios vermelhos.

Quatro tipos de violência simbólica puderam ser identificados nas imagens analisadas: a violência física, a violência de gênero, a apologia a regimes militaristas conservadores e o fortalecimento do antipetismo. Esses tipos não representam novidade - foram reedição de manifestações da mesma natureza em outros momentos da história brasileira, como a palavra de ordem de morte ao adversário, do perigo comunista, dos valores militaristas e facistas. O capítulo novo em tais manifestações foi a violência de gênero, uma vez que Dilma foi a primeira presidente do sexo feminino no país.

Não podendo nos estender muito neste espaço, trazemos alguns exemplos das quatro violências identificadas:

1. Violência física - a extinção do outro: trata-se do desejo, representado verbal ou graficamente, de matar, enforcar, torturar, chutar a bunda, enterrar, bater. Também se evocou o suicídio como saída para Dilma.

2. Violência de gênero: registramos aqui o afloramento de violências cometidas especificamente contra figuras femininas, de ordem sexual e estética. Agride-se a mulher ressaltando seu aspecto físico e/ou colocando-a como objeto de uso sexual. Assim, vemos que Dilma foi representada como gorda, velha, dentuça, bandida, comparada a animais e figuras mitológicas do mal (bruxa, dragão, rainha Jezabel, diabo). Também foi chamada de "puta" e ameaçada de violência sexual ${ }^{5}$.

5 A violência sexual pode ser "consumada", como na venda/distribuição de adesivos que simulam Dilma sendo penetrada pelo bico de bombas de gasolina, ou apenas verbal, com xingamentos como "vai tomar no c*", e outros. 
3. Apologia a regimes militaristas conservadores: palavras de ordem estampadas em cartazes, banners e faixas pediam a intervenção militar e o retorno da ditadura. Cartazes agradeciam o golpe de 1964 e manifestavam o desejo de volta dos generais. Movimentos neonazistas, como o Carecas do $A B C$, foram atraídos, voluntaria ou involuntariamente, para dentro das manifestações; registrou-se ainda a encenação do gesto da saudação nazista durante a execução do hino nacional.

4. Antipetismo - desejo do fim do PT: essa certamente foi a palavra de ordem mais forte e frequente das manifestações. É uma violência, pois atenta contra a diversidade partidária (na medida em que o partido atende aos requisitos constitucionais para se constituir como tal), e se utiliza de métodos destrutivos ignomínia, associações com sentido de reforçar uma imagem negativa e ameaçadora do partido, desvalorização dos adeptos. O combate ao PT se fez atentando contra a reputação de seus líderes, associando-os a lideranças comunistas e regimes vistos como ditatoriais (Hugo Chávez, Fidel Castro) e através de xingamentos aos eleitores (burros, petralhas). Adjetivos pejorativos que contêm as letras da sigla do partido (destacadas com a cor vermelha) buscaram colar significações (corruPTos, incomPTentes etc.), e foi convocado um "despetizamento" do Brasil, uma praga a ser eliminada do país.

\section{Crenças e verdade}

Distinguindo-se nitidamente de 2013, quando as motivações que impulsionaram as manifestações foram difusas e embrionárias, em 2015 as ações empreendidas se mostraram guiadas por propósitos bastante nítidos. Avançando na luta pela mudança, as crenças que se consolidaram estão no campo do pensamento conservador, exacerbando a intolerância para com a diferença.

Poder-se-ia dizer que foi uma intolerância dirigida, justificada pelo mal que se visava extirpar, ou seja foram a ação e os crimes do PT, de Lula e de Dilma que motivaram e desculparam essa reação tão violenta ("a corja que achaca e destrói o país"). Os valores que sobressaem, no entanto, indicam que não se trata de uma reação pontual, mas uma reação e uma intervenção dentro de um projeto de poder mais extenso, cimentado por um consenso, por uma verdade.

Retomando o que foi dito por James, a verdade é resultado de consensos últimos, e marcada por uma concordância com a realidade. Uma verdade "acontece" com uma ideia; está alicerçada em crenças e convicções.

No caso analisado, qual é a ideia que concorda com a realidade, e portanto se torna verdade? A ideia é de que o Brasil está em crise (e existe de fato uma crise econômica que nos ronda); de que existe corrupção solapando instituições públicas e roubando o dinheiro público (as denúncias da Lava Jato não deixam 
dúvidas de que houve uma corrupção grande na Petrobras, que empreiteiras e grandes empresas pagam propinas a funcionários dos órgãos públicos etc); de que, estando no poder há mais de uma década, o PT é responsável pelo funcionamento das empresas estatais e pelo comportamento das pessoas nomeadas. A costura desses pontos (aqui apenas sumariados de forma simplificada) indica que a crise foi provocada pelo PT, os roubos foram promovidos por ele, os petistas são os ladrões, o partido deve ser eliminado. É uma construção lógica, e faz sentido. A concordância de uma ideia com a realidade, nos diz o James, é constituída pela conjunção de elementos numa ordenação que atende à demanda de compreensão e orienta uma forma de lidar com a realidade.

Sabemos que essa conclusão não é a única possível, que muitos não concordam com ela, que ela é direcionada e serve a propósitos. Sem dúvida, ideias diferentes e concorrentes expressam e exprimem de forma totalmente diversa o que está ocorrendo no Brasil; a narrativa do governo petista pode ser construída e contada de outra maneira. Mas, nos lembra James, quando duas ideias concorrem para expressar uma experiência, é escolhida aquela que se mostra mais adequada para o encaminhamento de uma ação e para a obtenção de resultados mais promissores.

Ora, para a oposição, para partidos, grupos econômicos e setores de classe que disputam o poder e querem preservar seus lucros e privilégios, a narrativa da "corja que achaca o país" é a mais positiva e funcional. E esses sujeitos tiveram elementos disponíveis para torná-la verdade, inclusive porque detêm o controle da mídia, ou seja, estão equipados com dispositivos poderosos de informação e formação da opinião pública. Opiniões se formam com informações e evidências tornadas plausíveis e associadas a aspectos tangíveis da realidade vivida. 0 quadro contemporâneo (que não cabe aqui recuperar, mas que é muito diferente, por exemplo, de 2005, quando estourou o chamado "escândalo do mensalão") se mostrou um ambiente favorável para o fortalecimento e credibilidade da "ideia" (leitura de realidade) desenvolvida por um setor da sociedade e que busca se implantar como a melhor leitura, em concordância com o real.

Sabemos que essa narrativa que a mídia veicula se impõe com força de verdade para um grupo muito maior do que aquele efetivamente beneficiado com tal versão. Esse grupo - os indivíduos de classe média que foram para as ruas, que batem panela em seus apartamentos bem equipados - teria sido ludibriado? Não, trata-se de um posicionamento alicerçado em crenças. O comportamento suscitado e evocado (as ações de repúdio ao PT e o desejo de afastamento da presidenta) é compelido por crenças conservadoras sólidas, que distinguem e hierarquizam pessoas conforme sua origem e inserção social, sua etnia e cor de pele, seu gênero e orientação sexual. Crenças que valorizam o alto da pirâmide e aspiram a ele, e expressam horror à ideia de rebaixamento ou de aproximação 
com as classes subalternas. As crenças e valores da classe média brasileira têm profunda afinidade com os projetos da elite dominante, o que torna a primeira uma receptora muito adequada para as ideias (e a verdade) da segunda.

De forma sumária, podemos dizer que existem três formas de convivência com a diferença: a aceitação indiferente do outro; o respeito e acolhimento; a negação e destruição (BRANDÃO, 2005). De forma lamentável, a verdade que se consolida, em um dos desdobramentos de 2013, e se expressa em 2015, é coercitiva e totalitária e exprime o desejo de destruição do outro.

O cenário pacífico das manifestações contrasta apenas aparentemente com a violência simbólica que elas emitem. Essa manifestação ordeira não é pacífica, pois todo ordenamento é (de forma mais ou menos intensa) totalitário - a implantação de uma ordem exclui outras alternativas, posicionamentos e perspectivas.

Finalizando, é preciso dizer que as manifestações de 2015 expressam apenas um dos desdobramentos das jornadas de junho de 2013, do horizonte que elas continham potencialmente. Outras ações ocorreram e estão em curso; para citar apenas um exemplo, lembremos da ocupação de escolas pelos estudantes paulistas em novembro de 2015, num forte movimento de resistência contra o plano de reforma do ensino proposto pelo governo Alckmin. Esses desdobramentos - outras consequências do afloramento do desejo de mudança e do sentimento de adesão à necessidade de transformações sociais profundas, a luta contra o retrocesso e por uma mudança em direção ao avanço - até então não se consolidaram na mesma proporção, não geraram crenças suficientemente sólidas para articular sujeitos e orientar outras ações de forma mais contundente.

É tarefa daqueles que portam outras ideias, residuais que sejam, e que resistem, fazê-las avançar no sentido de que cheguem a acontecer como verdade para amplos setores da sociedade brasileira, e sejam instrumentadoras de novas ações. 


\section{Referências}

BATESON, G. "Uma teoria sobre brincadeira e fantasia". In: RIBEIRO, B.; GARCEZ, P. (org.). Sociolingüística interacional. São Paulo: Loyola, 2002.

BERGER, P.; LUCKMAN, T. A construção social da realidade. 6a ed. Petrópolis: Vozes, 1985.

BRANDÃO, J. L. "A tradição da diversidade cultural: ensaio de tipologia". In: LOPES, A. H.; CALABRE, L. (orgs.). Diversidade brasileira. Rio de Janeiro: Edições Casa de Rui Barbosa, 2005. Disponível em: http://150.164.100.248/jlinsbrandao/JLB_ diversidade_cultural.pdf.

CASTELLS, M. Redes de indignação e esperança. Rio de Janeiro: Paz e Terra, 2012.

DORNELAS, R. Com ou sem vandalismo? Black bloc, acontecimento e disputa de sentido. Dissertação (Mestrado). Universidade Federal de Minas Gerais, Belo Horizonte, 2015.

GOFFMAN, E. A representação do eu na vida cotidiana. Petrópolis: Vozes, 1996.

GOFFMAN, E. Os quadros da experiência social. Petrópolis: Vozes, 2012.

JAMES, W. "The sentiment of rationality". In: JAMES, W. The will to believe and other essays in popular philosophy. New York: Longmans, Green and Co, 1905. p. 63-107.

MADELRIEUX, S. William James. L'attitude empiriste. Paris: PUF, 2008.

NOGUEIRA, M. A. As ruas e a democracia: ensaios sobre o Brasil contemporâneo. Rio de Janeiro: Contraponto, 2013.

PUTNAM, H. "A teoria da verdade de James". In: PUTNAN, R. A. (Org.). William James. Aparecida: Ideias e Letras, 2010.

RODRIGUES, E. A. P. 2014 será maior: uma análise dos ecos das manifestações brasileiras. Monografia (Graduação). Universidade Federal de Minas Gerais, Belo Horizonte, 2015.

ZIZEK, S. Violência. São Paulo: Boitempo, 2014. 